\title{
Resonance between dithiocarbamates and thioureide mesomeres coupled to metal-hydrogen anagostic bond transforming under pressure
}

Szymon Sobczak, * Kinga Roszak, Andrzej Katrusiak*

Faculty of Chemistry, Adam Mickiewicz University, Uniwersytetu Poznańskiego 8, 61-614 Poznań, Poland

\begin{abstract}
The pressure-induced transformation of plane-square complex nickel(II) bis $(N, N$ diethyldithiocarbamate) between its soft dithiocarbamate (form I) and thioureide (form II) mesomeres is coupled to the interchange of anagostic $\mathrm{Ni} \cdots \mathrm{H}-\mathrm{C}$ interactions from methylene to the methyl group, respectively. At $1.23 \mathrm{GPa}$, the clearly visible giant anomalous compressibility of the crystal reveals a potential-energy difference of $5.4 \mathrm{kJmol}^{-1}$ between the two complex forms. The structural and spectroscopic results, which are supported by quantummechanical calculations, connect this solid-state phase transition with the mesomeric transition, and this is accompanied by the conformational transformation of anagostic $\mathrm{Ni} \cdots \mathrm{H}-\mathrm{C}$ rearrangement and formation of the charge-assisted $\mathrm{S}^{-} \cdots \mathrm{H}-\mathrm{C}$ bond under pressure.
\end{abstract}

\section{Introduction}

Elusive noncovalent metal-hydrogen interactions are associated with the properties of organometallic compounds and their catalytic chemistry. ${ }^{1-3}$ The discovery of agnostic bonds between carbon-hydrogen groups and transition metal centres has sparked interest in such interactions. ${ }^{3,4}$ The attractive character of these metal-hydrogen interactions is often assessed by the $\mathrm{C}-\mathrm{H} \cdots M$ (where $M$ is a metal centre) bond dimensions. Agnostic bonds are relatively short, $d(\mathrm{H} \cdots M)=1.8-2.3 \AA$, with bond angles $\angle(\mathrm{C}-\mathrm{H} \cdots M)$ between 90 and $140^{\circ}{ }^{3,5-8}$ Other $\mathrm{C}-\mathrm{H} \cdots M$ contacts that do not fulfil these criteria are described as anagostic. ${ }^{3,5-8}$ Initially, such longer contacts were assumed to be repulsive, but recently, anagostic bonds longer than $3 \AA$ 
were found to be attractive. ${ }^{6,9}$ However, the bond character strongly depends on the metal cation and its election configuration..$^{9}$ Anagostic bonds are frequent in square-planar $d^{8}$ metal complexes, usually formed by dithiocarbamate ligands. ${ }^{10-15}$

Owing to their easy synthetic routes, versatile complexation and attractive properties, dithiocarbamates are intensively studied and developed. The dithiocarbamate ligand, which is obtained in an exothermic reaction of $\mathrm{CS}_{2}$ and an amine in the presence of a base, is a highly attainable mono-anionic chelating agent that is capable of forming stable complexes with all transition-group, lanthanide, actinide and with the majority of main-group elements. ${ }^{16-18}$ All dithiocarbamates contain a characteristic disulfide moiety, which generally binds to metals in a symmetrical chelate fashion; however, other coordination modes, such as monodentate and aniso-bidentate modes, are much rarer but also possible. ${ }^{16,17}$ A considerable number (3350) of structures of ethyl dithiocarbamate (Et $\left.\mathbf{t}_{2} \mathbf{d t c}\right)$ complexes deposited in the Cambridge Structural Database (ver. 5.41) reflects the high interest in dithiocarbamates. Their broad spectrum of biological properties includes antibacterial and antifungal activities. ${ }^{16-19}$ The affinity of Et 2 dtc for various metals is utilized in metal poisoning treatments, such as excess copper (Wilson's disease) and nephrotoxicity that is associated with platinum-based chemotherapy. ${ }^{19,20}$ This property is also applied to separate different metal ions in high-performance liquid chromatography (HPLC) and capillary gas chromatography (GC). ${ }^{17,19}$ Metal dithiocarbamates are used in industrial processes, such as rubber vulcanization and pesticide syntheses. ${ }^{16,17,19,21,22}$

The exceptional stability of dithiocarbamates and their complexes is often connected with the resonance of two mesomeric forms, ${ }^{19,23}$ which depend on substituents, the metal oxidation state and the crystal environment. In the soft dithiocarbamate form (I), the negative charge is delocalized between the sulfur and carbon atoms, and the $\mathrm{C}$ atom is single-bonded to the $\mathrm{N}$ atom (Figure 1). The other thioureide form (II) can be distinguished by the nitrogen loneelectron pair delocalized to the sulfur atoms; this causes the $\pi$ character (double bond) to shift 
to the immonium bond $\mathrm{C}=\mathrm{N}^{+}$, in which the $\mathrm{C}$ atom bears two $\mathrm{S}$ atoms that share a negative charge (Figure 1). Importantly, transformation of the predominant hybrid form of ligands causes larger splitting of $d$ orbitals which changes the character of ligand from strong- to a weak-field ligand for mesomers I and II, respectively. ${ }^{19,23}$ It was shown that the prevailing contribution of form II to the overall electronic structure ensures that the dithiocarbamate anion is an effective ligand for metal complexation. ${ }^{11,17,19,24}$ The coexistence of the dithiocarbamate and thioureide forms in $\mathrm{Ni}\left(\mathbf{E t}_{2} \mathbf{d t c}\right)_{2}$ was first deduced from the IR spectra, in which the presence of a stretching band at $1522 \mathrm{~cm}^{-1,25}$ was located in-between the regions that are associated with $\mathrm{C}-\mathrm{N}$ and $\mathrm{C}=\mathrm{N}$ bonds. ${ }^{26}$ Later studies showed that the exceptionally high frequency of this band arises from the donation of electrons from the dithiocarbamate group to the nonbonding $p_{\mathrm{z}}$ molecular orbital of $\mathrm{Ni}$, and this result suggests that the dithiocarbamate mesomer prevails in the atmospheric form $\alpha$ of $\mathrm{Ni}\left(\mathbf{E t}_{\mathbf{2}} \mathbf{d t c}\right)_{2}{ }^{27,28}$

$\alpha-\mathrm{Ni}\left(\mathbf{E t}_{\mathbf{2}} \mathbf{d t c}\right)_{2}$

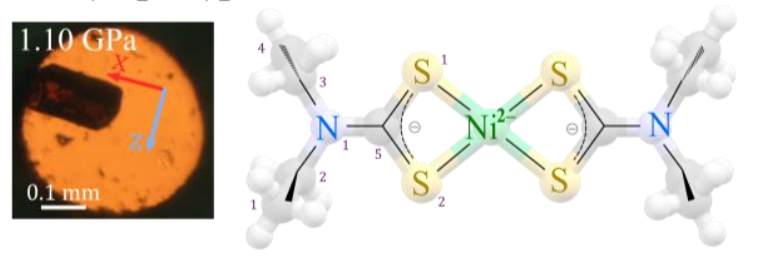

$\delta-\mathrm{Ni}\left(\mathbf{E t}_{\mathbf{2}} \mathbf{d t c}\right)_{2}$

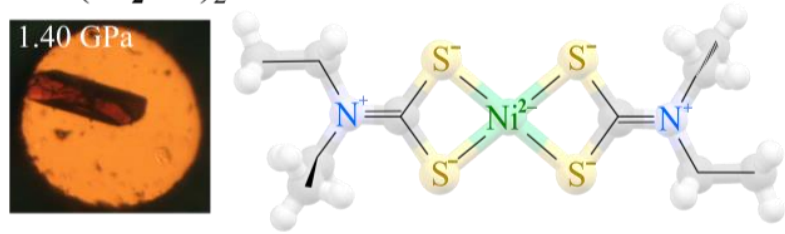

Figure 1. Nickel(II) bis( $N, N$-diethyldithiocarbamate) complex in phase $\alpha$ (top) and phase $\delta$ (bottom) with the corresponding resonance forms of Etzdtc ligand that are prevalent, as follows: form I, in which the negative charge is delocalized between two sulfur atoms; and form II, which contains an immonium bond $\mathrm{C}=\mathrm{N}^{+}$. The photographs show the strain in the transition between phases $\alpha$ and $\delta$ at $1.23 \mathrm{GPa}$ for the same single-crystal sample ( $c f$. Fig. S1). 
To better understand the preferences of $\mathbf{E t}_{2} \mathbf{d t c}$ mesomers and the properties of $\mathrm{C}-\mathrm{H} \cdots M$ interactions, we investigated the chemical and physical response of $\operatorname{nickel}(\mathrm{II}) \operatorname{bis}(\mathrm{N}, \mathrm{N}$ diethyldithiocarbamate) in a compressed crystal environment. Our single-crystal X-ray diffraction and Raman spectroscopic studies reveal that a giant strain was induced by the phase transition at $1.23 \mathrm{GPa}$ and resulted in the breaking and formation of anagostic bonds, a transformation in the Et $\mathbf{E} \mathbf{2} \mathbf{d t c}$ ligand conformation and a shift of the resonance structure toward the thioureide (II) mesomer, which is supported by the formation of charge-assisted $\mathrm{C}-\mathrm{H}^{\cdots} \cdot \mathrm{S}^{-}$ bonds.

\section{Discussion}

At ambient conditions, the nickel(II) bis( $N, N$-diethyldithiocarbamate) complex, $\mathrm{Ni}\left(\mathbf{E t} \mathbf{t}_{2} \mathbf{d t c}\right)_{2}$, crystallizes either as polymorph $\alpha$ (monoclinic space group $P 2{ }_{1} / c, Z=2$ ), ${ }^{11,29} \beta$ (tetragonal space group $\left.P 4_{2} / n, Z=4\right)^{24}$ or $\gamma$ (tetragonal space group $P 4 / m m m$, structure unknown). ${ }^{30}$ Polymorph $\alpha$ is more stable than polymorphs $\beta$ and $\gamma$. In polymorphs $\alpha$ and $\beta$, two $-\mathrm{CS}_{2}$ moieties of $\mathbf{E t} \mathbf{t}_{2} \mathbf{d t c}$ ligands isobidentate coordinate the $\mathrm{Ni}^{2+}$ cation in the form of a plane-square complex, in which the mesomeric form I of Et 2 dtc prevails. ${ }^{11,29}$ In polymorph $\alpha$, the unsaturated square coordination sphere of the low-spin $\mathrm{Ni}$ (II) cation is completed by two short symmetrically-related anagostic interactions $\mathrm{C}-\mathrm{H} \cdots \mathrm{Ni}$, complementing the octahedral configuration. These interactions contribute to the stability of the complex in the structure of polymorph $\alpha$ and at atmospheric pressure over a wide temperature range between 300 and 100 $\mathrm{K}$, and there are no signs of a phase transition (Fig. 2, Table S1 and Figs. S2-S3 in SI). 


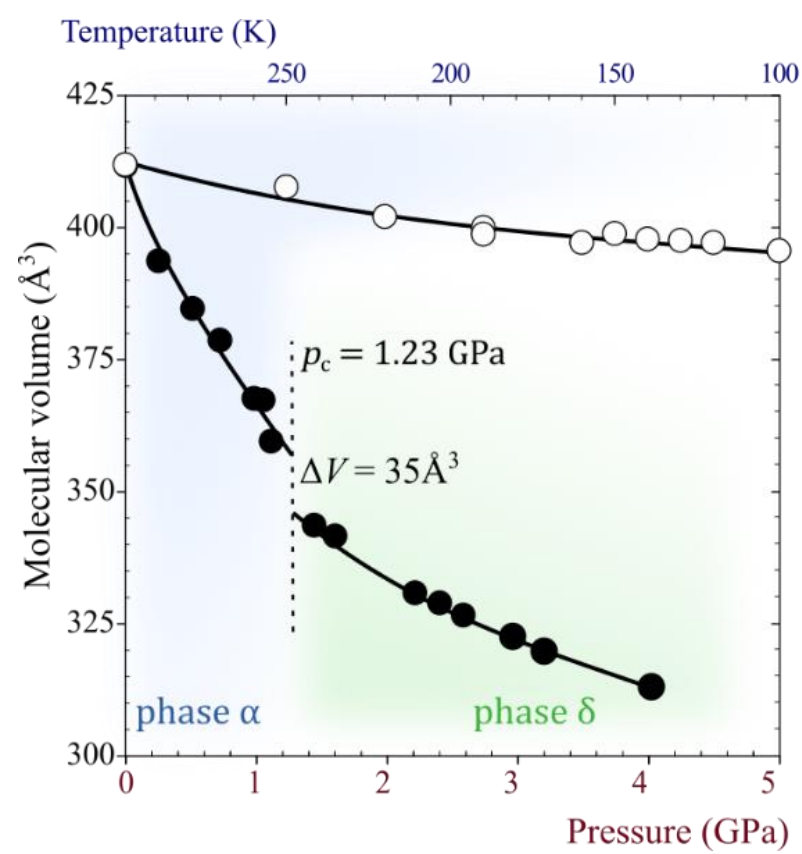

Figure 2. Compression (full symbols) and thermal expansion (open symbols) of the $\mathrm{Ni}\left(\mathbf{E t}_{2} \mathbf{d t c}\right)_{2}$ molecular volume. The vertical dashed line marks the critical pressure. All estimated standard deviations are smaller than the plotted symbols.

It is characteristic of phase $\alpha$ that the ethyl moieties of Et $\mathbf{2}$ dtc ligands are directed off the average plane of the complex to its opposite sides; at $1.11 \mathrm{GPa}$ torsion angles $\tau_{\mathrm{C} 1-\mathrm{C} 2-\mathrm{N} 1-\mathrm{C} 5}=$ $80.3(14)^{\circ}$ and $\tau_{\mathrm{C} 4-\mathrm{C} 3-\mathrm{N} 1-\mathrm{C} 5}=92.45(17)^{\circ}$. When the crystal is compressed above $1.23 \mathrm{GPa}$, it transforms to a new high-pressure phase $\delta$, retaining monoclinic space group $P 2{ }_{1} / c$. In phase $\delta$, the $\mathrm{Ni}\left(\mathbf{E t}_{2} \mathbf{d t c}\right)_{2}$ molecules reorient and become more tightly packed. At critical pressure $p_{c}$, the molecular conformation and the weakest intermolecular directional bonds abruptly yield when the voids collapse. In phase $\delta$ at $1.44 \mathrm{GPa}$, one methyl moves to the trans conformation: torsion angle $\tau_{\mathrm{C} 1-\mathrm{C} 2-\mathrm{N} 1-\mathrm{C} 5}$ rotates to $179.7(9)^{\circ}$, while $\tau_{\mathrm{C} 4-\mathrm{C} 3-\mathrm{N} 1-\mathrm{C} 5}$ is $87.4(12)^{\circ}$ (Fig. $\mathrm{S} 4$ in SI). The rotations of ethyls can be associated with the closer packing and $\mathrm{C}-\mathrm{H} \cdots \mathrm{Ni}$ interactions. Another conformational effect in phase $\delta$ is the flattering of the moiety of the N1-C5 bond and its adjacent atoms (Figures 1 and S5), which is indicative of the presence of the immonium bond $\mathrm{C}=\mathrm{N}^{+}$in the thioureide mesomer in phase $\delta$. Despite their relatively low statistical significance, other molecular dimensions in $\mathrm{Ni}\left(\mathbf{E t}_{\mathbf{2}} \mathbf{d t c}\right)_{2}$, which are plotted in Supporting Information 
Figures S5-S6, all consistently indicate that in phase $\delta$, the electronic resonance structure is shifted toward mesomeric type II. As suggested by Cotton and McCleverty, ${ }^{27}$ the transformation between these two forms can result from the donation of electrons from the electron-releasing $-\mathrm{NR}_{2}$ group, which forces the $\mathrm{S}$ atoms to accept electrons. ${ }^{31}$ According to this model, based on the interaction between the $\mathrm{Ni}$ (II) $4 p_{\mathrm{z}}$ molecular orbital and the sulfur $\pi$ orbitals, the capability to accept directional interactions along the $\mathrm{d}_{z}{ }^{2}$ orbital of the $\mathrm{Ni}$ (II) cation decreases.

Owing to the giant strain that is associated with the phase transition (Figs. 1 and S1 in SI), its critical pressure $p_{c}$ value could be precisely determined by visual observations. The transformation between phases $\alpha$ and $\delta$ is a typical isostructural $1^{\text {st }}$ order transition, which does not deteriorate the single-crystal quality. The relatively loose structure of polymorph $\alpha$, containing almost $8 \%$ of free voids of the total crystal volume (the contact-surface voids were calculated by Mercury ${ }^{32}$ for the probe-sphere radius of $0.9 \AA$ and step $0.1 \AA$ ), is consistent with the collapse-type of this transformation at $1.23 \mathrm{GPa}$. The voids located around the Etzdtc ligands are gradually reduced till $1.23 \mathrm{GPa}$ when the crystal is isothermally compressed to circa $85 \%$ of its initial volume. The Gibbs free energy of the crystal increases by the work contribution and can be associated with the $E_{p}$ barrier: for phase $\alpha$ from $0.1 \mathrm{MPa}$ to $p_{c}$ the work energy amounts to $11.2 \mathrm{kJmol}^{-1}$. Then, the molecular volume collapses by $35 \AA^{3}$ in phase $\delta$ (Fig. 1), which corresponds to an energy of $5.7 \mathrm{kJmol}^{-1}$. Thus, the energy difference between the ground states of phases $\alpha$ and $\delta$ is $6.3 \mathrm{kJmol}^{-1}$. Our DFT calculations for the isolated $\mathrm{Ni}\left(\mathbf{E t}_{2} \mathbf{d t c}\right)_{2}$ molecule in the fixed conformations derived from the structures of phases $\alpha$ and $\delta$ determined by us at 0.98 and $1.44 \mathrm{GPa}$, respectively, revealed that the intramolecular interactions significantly contribute to the $\Delta U$. The change in the mesomeric form of the complex increases the molecular energy by approximately $1.79 \mathrm{kJmol}^{-1}$. Therefore, the remaining $4.5 \mathrm{kJmol}^{-1}$ can be assigned to the energy of interactions between molecules and 
their crystal environment, which agrees well with the change in lattice energy $\left(\Delta E_{\mathrm{L}}=3.9 \mathrm{kJmol}^{-}\right.$ ${ }^{1}$ ), which was calculated with MiCMoS by the PIXEL program ${ }^{33}$ between 1.10 and $1.44 \mathrm{GPa}$ for phases $\alpha$ and $\delta$, respectively.

To further explore the high-pressure behaviour of $\mathrm{Ni}\left(\mathbf{E t}_{2} \mathbf{d t c}\right)_{2}$, including changes in the mesomeric states and anagostic interactions, we measured the high-pressure Raman spectra on a single-crystal sample that was compressed up to $2.1 \mathrm{GPa}$ (Figure 3) and compared the results with the spectra obtained from Gaussian $16^{34}$. Usually, a high pressure lowers the intensity of Raman signals, which shift toward higher wavenumbers as a result of the increased interactions and reduced amplitudes of vibrations in compressed environments.

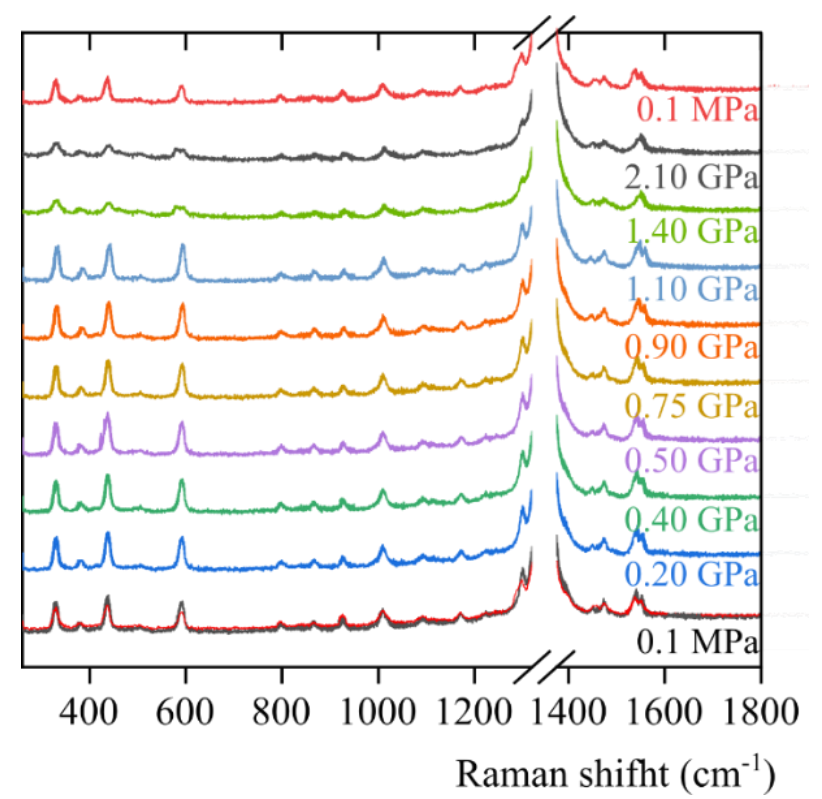

Figure 3. The Raman spectra of $\mathrm{Ni}(\mathbf{E t} \mathbf{2} \mathbf{d t c})_{2}$ was isothermally compressed in steps up to 2.10 $\mathrm{GPa}$. The upper spectrum was collected after the pressure was released.

The clear changes in the Raman spectra of $\mathrm{Ni}\left(\mathbf{E t}_{2} \mathbf{d t c}\right)_{2}$ above $p_{c}$ reflect the differences in the mesomeric form of $\mathbf{E} \mathbf{t}_{\mathbf{2}} \mathbf{d t c}$ between phase $\alpha$ and phase $\delta$ in the regions of $\mathrm{C}=\mathrm{N}$ stretching and $\mathrm{HCH}$ bending. ${ }^{35,36}$ In phase $\alpha$, the $\mathrm{C}=\mathrm{N}$ stretching bands at $1540 \mathrm{~cm}^{-1}$ are coupled with the $\mathrm{HCH}$ bending vibrations. ${ }^{37,38}$ Above $p_{c}$, in the region between 1470 and $1500 \mathrm{~cm}^{-1}$ the 
extinction of $\delta(\mathrm{HCH})\left(\mathrm{CH}_{3}\right),\left(\mathrm{CH}_{2}\right)+v_{\mathrm{s}}(\mathrm{C}=\mathrm{N})$ bands occurs, while $v_{\mathrm{as}}(\mathrm{C}=\mathrm{N})$ with some $\delta(\mathrm{HCH})\left(\mathrm{CH}_{2}\right)$ scissoring modes appears. ${ }^{39}$ Additionally, the presence of form II requires that the coordination S-Ni bonds differentiate. Indeed, in phase $\delta$, the Raman band at $350 \mathrm{~cm}^{-1}$, which are assigned as $\delta(\mathrm{SNiS})+\delta(\mathrm{NiSC})+v(\mathrm{CS})$, splits. Due to the progressive decrease in the metal-hydrogen distance, the band intensity at $570 \mathrm{~cm}^{-1}$, which is associated with $q\left(\mathrm{CH}_{3}\right)$ $+q\left(\mathrm{CH}_{2}\right)+v(\mathrm{CN})$ modes, is blue-shifted, consistently with the increased energy of the anagostic interactions involving the methylene group. Above $p_{\mathrm{c}}$, the strongly blue-shifted $\delta_{\text {ago }}\left(\mathrm{CH}_{3}\right)$ band marks the formation of a new methyl $\mathrm{C} 4-\mathrm{H} \cdots \mathrm{Ni}$ bond with a much lower energy.

It was recently established ${ }^{9,40}$ that the stabilization energy of anagostic interactions combines electrostatic Coulomb forces, contributing approximately $60 \%$ of the anagostic-bond energy, with the London dispersion and covalent-type charge delocalization, which jointly cover the remaining circa $40 \%$ of the stabilizing energy. The anagostic $\mathrm{Ni} \cdots \mathrm{H}-\mathrm{C}$ bond that is longer than $3 \AA$ can be attractive only when the repulsive Coulomb and steric (Pauli/kinetic repulsion) components are overcompensated by the process of $\sigma(\mathrm{C}-\mathrm{H}) \rightarrow \mathrm{Ni}\left(d_{\mathrm{z}}^{2}\right)$ donation together with the back transfer $\mathrm{Ni}\left(d_{\mathrm{z}}{ }^{2}\right) \rightarrow \sigma^{*}(\mathrm{C}-\mathrm{H}) .{ }^{9}$ According to quantum-mechanical calculations, ${ }^{9,40}$ this covalent-type charge delocalization is capable of stabilizing the anagostic interactions. Their attractive character is corroborated by the pressure-induced phase transition between different motives of the anagostic $\mathrm{Ni} \cdots \mathrm{H}-\mathrm{C}$ bonds (Figure 4 ), which significantly contribute to the cohesion forces in the crystal structure of $\mathrm{Ni}(\mathbf{E t} \mathbf{t} \mathbf{d t c})_{2}$. 


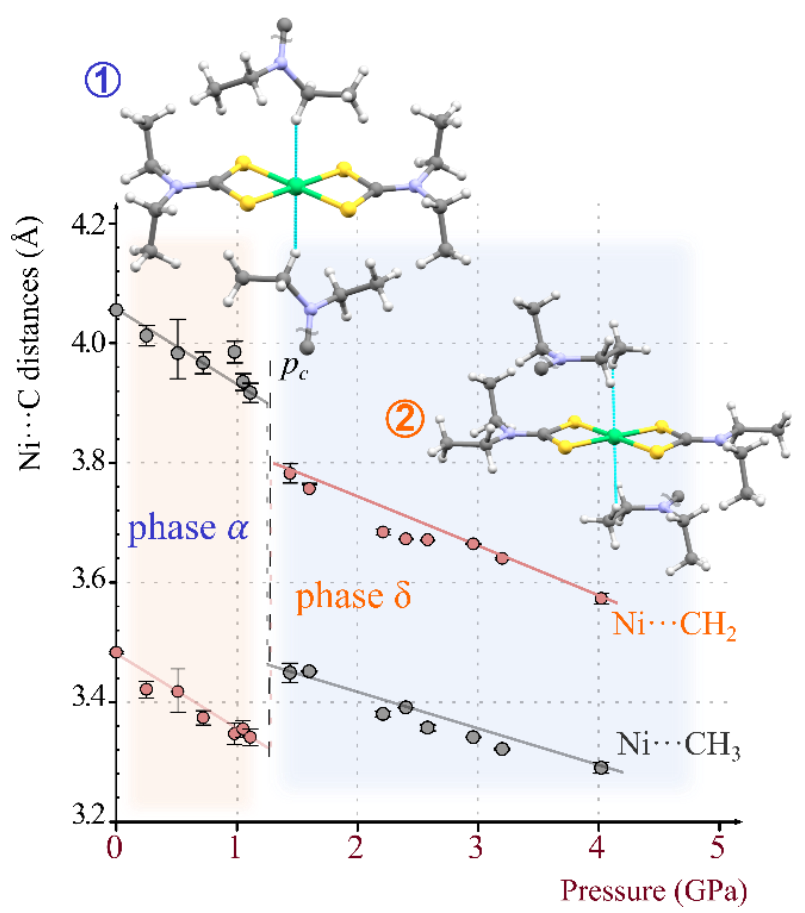

Figure 3. The agnostic $\mathrm{C}-\mathrm{H} \cdots \mathrm{Ni}$ distances as a function of pressure (the temperature dependence is shown Fig. S7 in SI). The insets show the Ni-coordination spheres in phases $\alpha$ and $\delta$.

The intermolecular interactions energies in phases $\alpha$ and $\delta$, according to the computations within platform MiCMoS with the PIXEL program, ${ }^{33}$ show that the molecules connected by the anagostic bond $\mathrm{Ni} \cdots \mathrm{H}-\mathrm{C}$ are the main contributors to the cohesion forces (Figure 5, $c f$. Table S3 in SI). Interestingly, such strong interactions, when compared to other intermolecular contacts that commonly occur in organic crystals, are unlikely to be destabilized during the phase transition. ${ }^{41}$ However, when the $\mathrm{Ni}\left(\mathbf{E t}_{2} \mathbf{d t c}\right)_{2}$ crystal transforms to phase $\delta$, the changed $\mathrm{H}$-donor in anagostic $\mathrm{Ni} \cdots \mathrm{H}-\mathrm{C}$ bonds results in the significantly increased attraction between newly molecules. The next strongest attraction in phase $\delta$, absent in phase $\alpha$, is the chargeassisted $\mathrm{C}-\mathrm{H} \cdots \mathrm{S}^{-}$bond. Its presence in phase $\delta$ is consistent with the resonance form II of Etzdtc. 
(a) phase $\alpha$
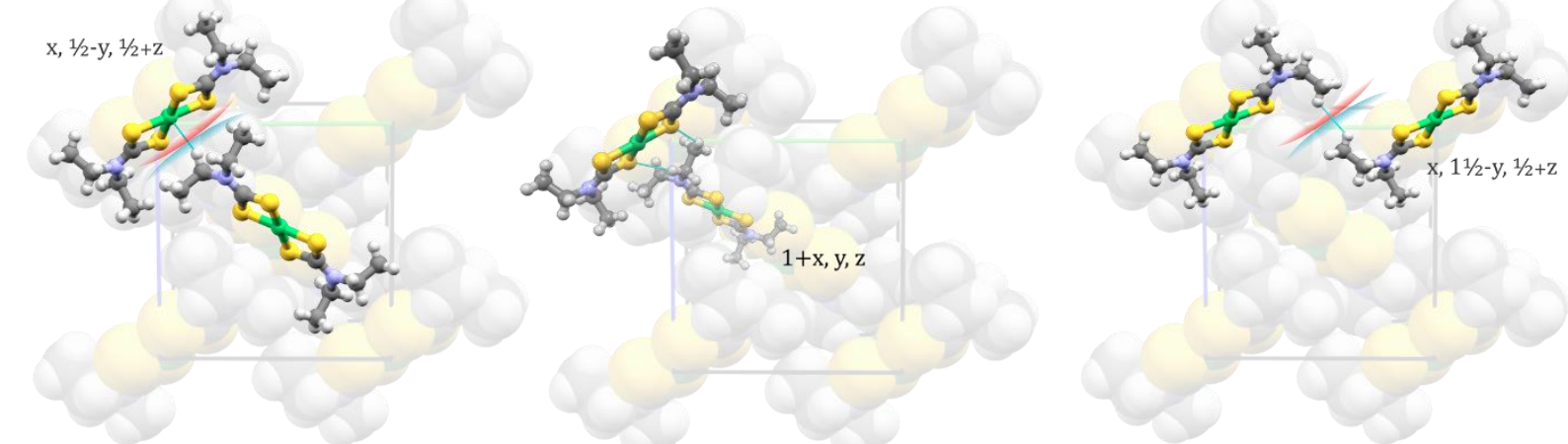

$$
\begin{aligned}
& 0.1 \mathrm{MPa} \quad E_{\text {tot }}=-28.6 \mathrm{kJmol}^{-1} \\
& E_{C}=-27.5 \mathrm{kJmol}^{-1} \quad E_{d i s}=-44.4 \mathrm{kJmol}^{-1} \\
& E_{p o l}=-12.2 \mathrm{kJmol}^{-1} \quad E_{\text {rep }}=55.4 \mathrm{kJmol}^{-1} \\
& 1.11 \mathrm{GPa} \quad E_{\text {tot }}=-25.6 \mathrm{kJmol}^{-1} \\
& E_{C}=-39.5 \mathrm{kJmol}^{-1} \quad E_{\text {dis }}=-56.0 \mathrm{kJmol}^{-1} \\
& E_{\text {pol }}=-18.1 \mathrm{kJmol}^{-1} \quad E_{\text {rep }}=87.9 \mathrm{kJmol}^{-1}
\end{aligned}
$$

$$
\begin{aligned}
& E_{\text {tot }}=-20.5 \mathrm{kJmol}^{-1} \\
& E_{C}=-18.9 \mathrm{kJmol}^{-1} \quad E_{\text {dis }}=-27.5 \mathrm{kJmol}^{-1} \\
& E_{p o l}=-8.7 \mathrm{kJmol}^{-1} \quad E_{\text {rep }}=34.6 \mathrm{kJmol}^{-1} \\
& E_{\text {tot }}=-20.4 \mathrm{kJmol}^{-1} \\
& E_{C}=-28.0 \mathrm{kJmol}^{-1} \quad E_{\text {dis }}=-37.1 \mathrm{kJmol}^{-1} \\
& E_{p o l}=-13.9 \mathrm{kJmol}^{-1} \quad E_{\text {rep }}=58.6 \mathrm{kJmol}^{-1}
\end{aligned}
$$$$
E_{\text {tot }}=-7.4 \mathrm{kJmol}^{-1}
$$$$
E_{C}=-5.2 \mathrm{kJmol}^{-1} \quad E_{\text {dis }}=-34.8 \mathrm{kJmol}^{-1}
$$$$
E_{\text {pol }}=-13.2 \mathrm{kJmol}^{-1} \quad E_{\text {rep }}=45.8 \mathrm{kJmol}^{-1}
$$$$
E_{\mathrm{tot}}=-8.0 \mathrm{kJmol}^{-1}
$$

$E_{C}=-18.8 \mathrm{kJmol}^{-1} \quad E_{\text {dis }}=-47.2 \mathrm{kJmol}^{-1}$

$E_{p o l}=-24.2 \mathrm{kJmol}^{-1} \quad E_{\text {rep }}=82.2 \mathrm{kJmol}^{-1}$

(b) phase $\delta$
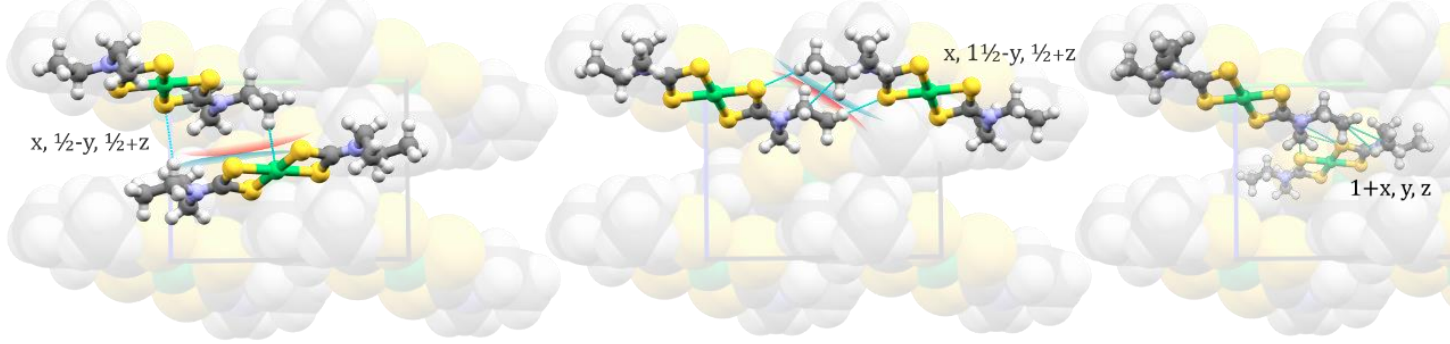
$1.44 \mathrm{GPa}$
$E_{\text {tot }}=-34.3 \mathrm{kJmol}^{-1}$
$E_{C}=-47.8 \mathrm{kJmol}^{-1} \quad E_{d i s}=-64.1 \mathrm{kJmol}^{-1}$
$E_{\text {pol }}=-23.6 \mathrm{kJmol}^{-1} \quad E_{\text {rep }}=101.1 \mathrm{kJmol}^{-1}$

$E_{\text {tot }}=-18.5 \mathrm{kJmol}^{-1}$

$4.02 \mathrm{GPa} \quad E_{\text {tot }}=-21.6 \mathrm{kJmol}^{-1}$
$E_{C}=-75.4 \mathrm{kJmol}^{-1} \quad E_{\text {dis }}=-84.4 \mathrm{kJmol}^{-1}$
$E_{\text {pol }}=-38.8 \mathrm{kJmol}^{-1} \quad E_{\text {rep }}=177.0 \mathrm{kJmol}^{-1}$

$E_{C}=-20.0 \mathrm{kJmol}^{-1} \quad E_{d i s}=-24.7 \mathrm{kJmol}^{-1}$

$E_{\text {pol }}=-10.9 \mathrm{kJmol}^{-1} \quad E_{\text {rep }}=37.2 \mathrm{kJmol}^{-1}$

$$
E_{\text {tot }}=-15.2 \mathrm{kJmol}^{-1}
$$

$E_{\text {tot }}=-15.0 \mathrm{kJmol}^{-1}$

$E_{C}=-20.5 \mathrm{kJmol}^{-1} \quad E_{d i s}=-31.8 \mathrm{kJmol}^{-1}$

$E_{p o l}=-10.9 \mathrm{kJmol}^{-1} \quad E_{\text {rep }}=48.2 \mathrm{kJmol}^{-1}$

$E_{C}=-28.1 \mathrm{kJmol}^{-1} \quad E_{\text {dis }}=-30.8 \mathrm{kJmol}^{-1}$

$E_{\text {pol }}=-16.8 \mathrm{kJmol}^{-1} \quad E_{\text {rep }}=60.5 \mathrm{kJmol}^{-1}$

$$
E_{\text {tot }}=-9.8 \mathrm{kJmol}^{-1}
$$

$E_{C}=-33.0 \mathrm{kJmol}^{-1} \quad E_{\text {dis }}=-42.3 \mathrm{kJmol}^{-1}$ $E_{p o l}=-19.4 \mathrm{kJmol}^{-1} \quad E_{\text {rep }}=84.9 \mathrm{kJmol}^{-1}$

Figure 6. Total energy $\left(E_{\mathrm{tot}}\right)$ of the intermolecular interactions, as well as their Coulomb, polarization, dispersion and repulsion parts, between adjacent molecules in (a) phase $\alpha$ at 0.1 $\mathrm{MPa}$ and $1.1 \mathrm{GPa}$ and (b) in phase $\delta$ at 1.4 and $4.02 \mathrm{GPa}$ (cf. Table S3).

\section{Conclusions}

It is remarkable that the anagostic $\mathrm{Ni} \cdots \mathrm{H}-\mathrm{C}$ bond remains the strongest cohesion force in the structure of representative square-planar $\mathrm{d}^{8}-\mathrm{ML}_{4}$ molecular complex $\mathrm{Ni}\left(\mathbf{E t}_{2} \mathbf{d t c}\right)_{2}$, as it undergoes the pressure-induced transition at $1.23 \mathrm{GPa}$ between the $\alpha$ and $\delta$ phases. This phase transition is coupled to the exchange of the anagostic $\mathrm{H}$-donor between methylene and methyl 
groups. It is plausible that the accompanying change in the Etzdtc conformation and shift of the resonance electronic structure toward thioureide form II is connected to the charge-assisted bonds $\mathrm{C}-\mathrm{H}^{\cdots} \mathrm{S}^{-}$in phase $\delta$. This transition demonstrates the sensitivity of conformational and electronic features to their environment, and this sensitivity can drastically affect the chemical properties of compounds.

\section{Experimental}

\section{Synthesis}

All substrates were purchased and used without further purification.

\section{Preparation of potassium N,N'-diethyldithiocarbamate [K(Et2dtc)]}

Carbon disulfide $\left(1.21 \mathrm{~cm}^{3}\right)$, and potassium hydroxide $(1.12 \mathrm{~g})$ were added dropwise to a solution of the secondary diethyl amine $\left(2.07 \mathrm{~cm}^{3}\right)$ in methanol $(15 \mathrm{ml})$, and the mixture was kept in an ice bath throughout the process. The pure product $[\mathrm{K}(\mathbf{E t} \mathbf{2} \mathbf{d t c})]$ was obtained after recrystallization from methanol.

\section{Preparation of the $\mathrm{Ni}(\mathrm{II}) \mathrm{N}, \mathrm{N}^{\prime}$-diethyldithiocarbamate [Ni(Et $\left.\mathbf{E t t c}_{2}\right)_{2}$}

$\mathrm{NiCl}_{2} \cdot 6 \mathrm{H}_{2} \mathrm{O}(0.53 \mathrm{~g})$ was dissolved in methanol $(5 \mathrm{ml})$ and added dropwise to a solution of $\left[\mathrm{K}\left(\mathbf{E t} \mathbf{t}_{2} \mathbf{d t c}\right)\right]\left(0.5 \mathrm{~g}\right.$, in $10 \mathrm{ml}$ methanol). Single crystals of [ $\left.\mathrm{Ni}\left(\mathbf{E t}_{2} \mathbf{d t c}\right)_{2}\right]$ precipitated from the reaction mixture after 2 weeks.

\section{High-pressure structural measurements}

A single crystal of $\mathrm{Ni}(\mathbf{E t} \mathbf{2} \mathbf{2 d t c})_{2}$ was gradually compressed in a Merrill-Bassett diamond-anvil cell, ${ }^{42}$ modified by mounting the anvils directly on steel backing plates with conical windows. ${ }^{43}$ The gasket was made of $0.20 \mathrm{~mm}$ thick Inconel foil with a spark-eroded hole $0.45 \mathrm{~mm}$ in diameter. Glycerol was used as the hydrostatic medium. Pressure in the DAC chamber was calibrated by the ruby-fluorescence method ${ }^{44,45}$ with a Photon Control Inc. spectrometer, 
affording an accuracy of $0.02 \mathrm{GPa}$; the pressure was calibrated before and after each data collection point.

The structures of the high-pressure phases were determined by single-crystal X-ray diffraction. Single-crystal low-temperature data were recorded on Oxford Diffraction Xcalibur and SuperNova diffractometers with low-temperature Cryosystem attachments. Single-crystal high-pressure data were recorded on diffractometers KUMA KM4-CCD and Xcalibur, both equipped with EOS-CCD detectors, according to the procedure described previously. ${ }^{46}$ Software CrysAlisPro ${ }^{47}$ was used to collect diffraction data and their preliminary reduction. The crystal sample reflections that overlapped with diamond reflections were eliminated, and corrections for the DAC and sample absorption as well as for the shadowing of the beams by the gasket were applied. The crystal structures were solved by the direct methods with program SHELXT $^{48}$ and refined by least-squares with SHELXL $^{49}$ by using Olex $2^{50}$ software. Anisotropic displacement factors were generally applied for non-hydrogen atoms. The $U_{\text {iso }}$ values of the $\mathrm{H}$ atoms were constrained to 1.2 times the $U_{e q}$ of their carrier atoms. Structural drawings were prepared using program Mercury CSD 4.0.5 ${ }^{51}$ The detailed crystallographic information has been deposited in the Cambridge Structural Database ${ }^{52}$ as supplementary publications CSD 2099800-2099822. Selected crystal data are listed in Table 1. The experimental and crystal details are listed in Table S1. 
Table 1. Selected crystal data of $\mathrm{Ni}\left(\mathbf{E t}_{2} \mathbf{d t c}\right)_{2}$ phase $\alpha$ and phase $\delta$, all determined at $296 \mathrm{~K}$.

\begin{tabular}{|c|c|c|c|c|c|c|c|}
\hline \multicolumn{2}{|l|}{ Phase } & Phase $\alpha$ & Phase $\alpha$ & Phase $\alpha$ & Phase $\alpha$ & Phase $\delta$ & Phase $\delta$ \\
\hline \multicolumn{2}{|c|}{ Pressure $(\mathrm{GPa})$} & 0.0001 & 0.25 & 0.98 & 1.11 & 1.44 & 4.02 \\
\hline \multicolumn{2}{|c|}{ Space group } & $P 2{ }_{1} / c$ & $P 2{ }_{1} / c$ & $P 2{ }_{1} / c$ & $P 2{ }_{1} / c$ & $P 2{ }_{1} / c$ & $P 2{ }_{1} / c$ \\
\hline \multirow[t]{4}{*}{ Unit cell } & $a(\AA)$ & $6.008(1)$ & $6.090(2)$ & $5.7981(5)$ & $5.7426(7)$ & $7.2673(7)$ & $7.002(1)$ \\
\hline & $b(\AA)$ & $11.441(2)$ & $11.356(3)$ & $11.316(1)$ & $11.260(3)$ & $11.271(1)$ & $11.043(3)$ \\
\hline & $c(\AA)$ & $11.543(2)$ & $11.429(5)$ & $11.284(3)$ & $11.203(2)$ & $8.404(3)$ & $8.101(6)$ \\
\hline & $\beta\left(^{\circ}\right)$ & $95.98(3)$ & $95.38(14)$ & $96.71(1)$ & $96.932(16)$ & $93.20(2)$ & $91.84(2)$ \\
\hline \multicolumn{2}{|l|}{$\mathrm{V}\left(\AA^{3}\right)$} & 789.120 & $787(3)$ & $735.3(2)$ & $719.1(3)$ & $687.3(3)$ & $626.1(5)$ \\
\hline \multicolumn{2}{|l|}{$Z / Z^{\prime}$} & $2 / 0.5$ & $2 / 0.5$ & $2 / 0.5$ & $2 / 0.5$ & $2 / 0.5$ & $2 / 0.5$ \\
\hline \multicolumn{2}{|c|}{$D_{\mathrm{x}}\left(\mathrm{g} \mathrm{cm}^{-3}\right)$} & 1.495 & 1.498 & 1.604 & 1.641 & 1.716 & 1.884 \\
\hline
\end{tabular}

\section{High-pressure Raman spectroscopy}

Raman spectra for the $\mathrm{Ni}\left(\mathbf{E t}_{2} \mathbf{d t c}\right)_{2}$ single-crystal sample compressed in glycerol were measured in a DAC equipped with low-fluorescence synthetic AII diamond culets. A customized Raman spectrometer equipped with laser M266 from Solar Laser Systems (785 nm) and a Hamamatsu Photonics multichannel detector was used.

\section{Ab Initio calculations}

The potential energy $\left(E_{p}\right)$ of the isolated $\mathrm{Ni}\left(\mathbf{E t}_{2} \mathbf{d t c}\right)_{2}$ molecule was calculated with program Gaussian 16 , Revision C. $01^{53}$ by applying the B3LYP basic set $6-311^{++} \mathrm{g}(\mathrm{d}, \mathrm{p})$. The energy values in a.u. were converted to $\mathrm{kJ} / \mathrm{mol}$ (1 a.u. $2625 \mathrm{~kJ} / \mathrm{mol}$ ). Graphical illustrations were prepared using program GaussView $6 .{ }^{34}$ The Raman spectra were calculated for the optimized molecular dimensions as well as separately for the fixed molecular coordinates from phase $\delta$.

The crystal intermolecular energies were calculated with the MiCMoS platform. ${ }^{54,55}$ Atomic positions were first retrieved from the CIF files for the measurements at $0.1 \mathrm{MPa}, 1.10,1.44$ and 4.02 GPa. All H-atoms were renormalized. The electron density calculations were 
performed in Gaussian $16^{34}$ with MP2/6-311++g(2d,2p) wavefunctions. The lattice energies were then calculated with the PIXEL method. ${ }^{33}$

\section{References}

1 M. Lein, Coord. Chem. Rev., 2009, 253, 625-634.

2 E. Clot and O. Eisenstein, pp. 1-36.

3 M. Brookhart, M. L. H. Green and G. Parkin, Proc. Natl. Acad. Sci., 2007, 104, 69086914.

4 J. F. Hartwig, Organotransition Metal Chemistry - From Bonding to Catalysis, University Science Books, California, 2010.

5 Y. Zhang, J. C. Lewis, R. G. Bergman, J. A. Ellman and E. Oldfield, Organometallics, 2006, 25, 3515-3519.

6 W. Scherer, A. C. Dunbar, J. E. Barquera-Lozada, D. Schmitz, G. Eickerling, D. Kratzert, D. Stalke, A. Lanza, P. Macchi, N. P. M. Casati, J. Ebad-Allah and C. Kuntscher, Angew. Chemie Int. Ed., 2015, 54, 2505-2509.

7 D. Braga, F. Grepioni, E. Tedesco, K. Biradha and G. R. Desiraju, Organometallics, 1997, 16, 1846-1856.

8 D. Braga and F. Grepioni, Acc. Chem. Res., 2000, 33, 601-608.

9 M. P. Mitoraj, M. G. Babashkina, K. Robeyns, F. Sagan, D. W. Szczepanik, Y. V. Seredina, Y. Garcia and D. A. Safin, Organometallics, 2019, 38, 1973-1981.

10 A. N. Gupta, V. Kumar, V. Singh, K. K. Manar, M. G. B. Drew and N. Singh, CrystEngComm, 2014, 16, 9299-9307.

11 A. Husain, S. A. A. Nami, S. P. Singh, M. Oves and K. S. Siddiqi, Polyhedron, 2011, 30, 33-40.

12 M. K. Yadav, G. Rajput, L. B. Prasad, M. G. B. Drew and N. Singh, New J. Chem., 2015, 39, 5493-5499.

13 V. Kumar, V. Singh, A. N. Gupta, M. G. B. Drew and N. Singh, Dalt. Trans., 2015, 44, 1716-1723.

14 S. K. Singh, M. G. B. Drew and N. Singh, CrystEngComm, 2013, 15, 10255.

15 G. Rajput, V. Singh, A. N. Gupta, M. K. Yadav, V. Kumar, S. K. Singh, A. Prasad, M. G. B. Drew and N. Singh, CrystEngComm, 2013, 15, 4676.

16 E. R. T. Tiekink, Appl. Organomet. Chem., 2008, 22, 533-550.

17 G. Hogarth, Mini-Reviews Med. Chem., 2012, 12, 1202-1215.

18 Thorn G. D. and Ludwig R. A., The dithiocarbamates and related compounds., Amsterdam; New York, Elsevier Publishing Co., 1962.

19 G. Hogarth, in Progress in Inorganic Chemistry, 2005, vol. 53, pp. 71-561. 
20 E. R. T. Tiekink, Appl. Organomet. Chem., 2008, 22, 533-550.

21 S. Sánchez-Cortés, M. Vasina, O. Francioso and J. . García-Ramos, Vib. Spectrosc., 1998, 17, 133-144.

22 J. M. Matxain, J. M. Asua and F. Ruipérez, Phys. Chem. Chem. Phys., 2016, 18, 17581770 .

23 D. Coucouvanis and J. P. Fackler, Inorg. Chem., 1967, 6, 2047-2053.

24 M. N. I. Khan, J. P. Fackler Jnr, H. H. Murray, D. D. Heinrich and C. Campana, Acta Crystallogr. Sect. C Cryst. Struct. Commun., 1987, 43, 1917-1919.

25 G. Hogarth, Prog. Inorg. Chem., 2005, 71-561.

26 J. CHATT, L. A. DUNCANSON and L. M. VENANZI, Nature, 1956, 177, 10421043.

27 F. A. Cotton and J. A. McCleverty, Inorg. Chem., 1964, 3, 1398-1402.

28 J. Adeyemi and D. Onwudiwe, Molecules, 2018, 23, 2571.

29 M. Bonamico, G. Dessy, C. Mariani, A. Vaciago and L. Zambonelli, Acta Crystallogr., 1965, 19, 619-626.

30 A. Vaciago and A. Fasana, Atti. Accad. Naz. Lincei, Cl. Sci. Fis., Mat. Natur., Rend., 1958, 25, 528-530.

31 D. Coucouvanis and J. P. Fackler, Inorg. Chem., 1967, 6, 2047-2053.

32 C. F. Macrae, I. J. Bruno, J. A. Chisholm, P. R. Edgington, P. McCabe, E. Pidcock, L. Rodriguez-Monge, R. Taylor, J. Van De Streek and P. A. Wood, J. Appl. Crystallogr., 2008, 41, 466-470.

33 A. Gavezzotti, Mol. Phys., 2008, 106, 1473-1485.

34 R. Dennington, T. A. Keith and J. M. Millam, 2019.

35 L. Tosi and A. Garnier, J. Chem. Soc. Dalt. Trans., 1978, 53.

36 M. Mylrajan, J. Mol. Struct., 1995, 348, 257-260.

37 Y. Suffren, F. G. Rollet and C. Reber, Comments Inorg. Chem., 2011, 32, 246-276.

38 R. Kellner, G. St. Nikolov and N. Trendafilova, Inorganica Chim. Acta, 1984, 84, 233-239.

39 F. Baril-Robert, M. A. Radtke and C. Reber, J. Phys. Chem. C, 2012, 116, 2192-2197.

40 G. dos Passos Gomes, G. Xu, X. Zhu, L. M. Chamoreau, Y. Zhang, O. Bistri-Aslanoff, S. Roland, I. V. Alabugin and M. Sollogoub, Chem. - A Eur. J., 2021, 27, 8127-8142.

41 M. Kaźmierczak and A. Katrusiak, CrystEngComm, 2015, 17, 9423-9430.

42 L. Merrill and W. A. Bassett, Rev. Sci. Instrum., 1974, 45, 290-294.

43 A. Katrusiak, Acta Crystallogr. Sect. A Found. Crystallogr., 2008, 64, 135-148.

44 G. J. Piermarini, S. Block, J. D. Barnett and R. A. Forman, J. Appl. Phys., 1975, 46, 2774-2780. 
46 A. Budzianowski and A. Katrusiak, in High-Pressure Crystallography, Springer Netherlands, Dordrecht, 2004, pp. 101-112.

47 CrysAlisPro Rigaku Oxford Diffraction, 2015.

48 G. M. Sheldrick, Acta Crystallogr. Sect. A Found. Adv., 2015, 71, 3-8.

49 G. M. Sheldrick, Acta Crystallogr. Sect. C Struct. Chem., 2015, 71, 3-8.

50 O. V. Dolomanov, L. J. Bourhis, R. J. Gildea, J. A. K. Howard and H. Puschmann, J. Appl. Crystallogr., 2009, 42, 339-341.

51 C. F. Macrae, I. Sovago, S. J. Cottrell, P. T. A. Galek, P. McCabe, E. Pidcock, M. Platings, G. P. Shields, J. S. Stevens, M. Towler and P. A. Wood, J. Appl. Crystallogr., 2020, 53, 226-235.

52 C. R. Groom, I. J. Bruno, M. P. Lightfoot and S. C. Ward, Acta Crystallogr. Sect. B Struct. Sci. Cryst. Eng. Mater., 2016, 72, 171-179.

53 M. J. Frisch, G. W. Trucks, H. B. Schlegel, G. E. Scuseria, M. A. Robb, J. R. Cheeseman, G. Scalmani, V. Barone, G. A. Petersson, H. Nakatsuji, X. Li, M. Caricato, A. V Marenich, J. Bloino, B. G. Janesko, R. Gomperts, B. Mennucci, H. P. Hratchian, J. V Ortiz, A. F. Izmaylov, J. L. Sonnenberg, D. Williams-Young, F. Ding, F. Lipparini, F. Egidi, J. Goings, B. Peng, A. Petrone, T. Henderson, D. Ranasinghe, V. G. Zakrzewski, J. Gao, N. Rega, G. Zheng, W. Liang, M. Hada, M. Ehara, K. Toyota, R. Fukuda, J. Hasegawa, M. Ishida, T. Nakajima, Y. Honda, O. Kitao, H. Nakai, T. Vreven, K. Throssell, J. A. Montgomery Jr., J. E. Peralta, F. Ogliaro, M. J. Bearpark, J. J. Heyd, E. N. Brothers, K. N. Kudin, V. N. Staroverov, T. A. Keith, R. Kobayashi, J. Normand, K. Raghavachari, A. P. Rendell, J. C. Burant, S. S. Iyengar, J. Tomasi, M. Cossi, J. M. Millam, M. Klene, C. Adamo, R. Cammi, J. W. Ochterski, R. L. Martin, K. Morokuma, O. Farkas, J. B. Foresman and D. J. Fox, 2016.

54 A. Gavezzotti and L. Lo Presti, J. Appl. Crystallogr., 2019, 52, 1253-1263.

55 A. Gavezzotti, L. Lo Presti and S. Rizzato, CrystEngComm, 2020, 22, 7350-7360. 


\section{TOC}

The pressure-induced phase transformation, couples the shift of the mesomeric form of ligand and interchanges the anagostic $\mathrm{Ni} \cdots \mathrm{H}-\mathrm{C}$ interactions in plane-square $\mathrm{Ni}(\mathrm{II})$ complex.

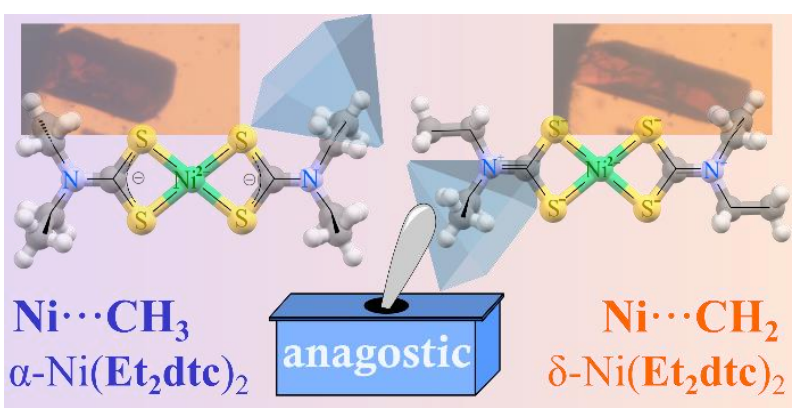

